\title{
VEGF AND BMP-2 PROMOTE BONE REGENERATION BY FACILITATING BONE MARROW STEM CELL HOMING AND DIFFERENTIATION
}

\author{
Wenjie Zhang ${ }^{1,2, \#, ~ C h a o ~ Z h u, ~}{ }^{3, \#}$, Yiqun $\mathrm{Wu}^{4}$, Dongxia Ye ${ }^{4}$, Shaoyi Wang ${ }^{4}$, Duohong Zou ${ }^{4}$ Xiuli Zhang ${ }^{2}$, \\ David L. Kaplan ${ }^{5, *}$ and Xinquan Jiang ${ }^{1,2, *}$

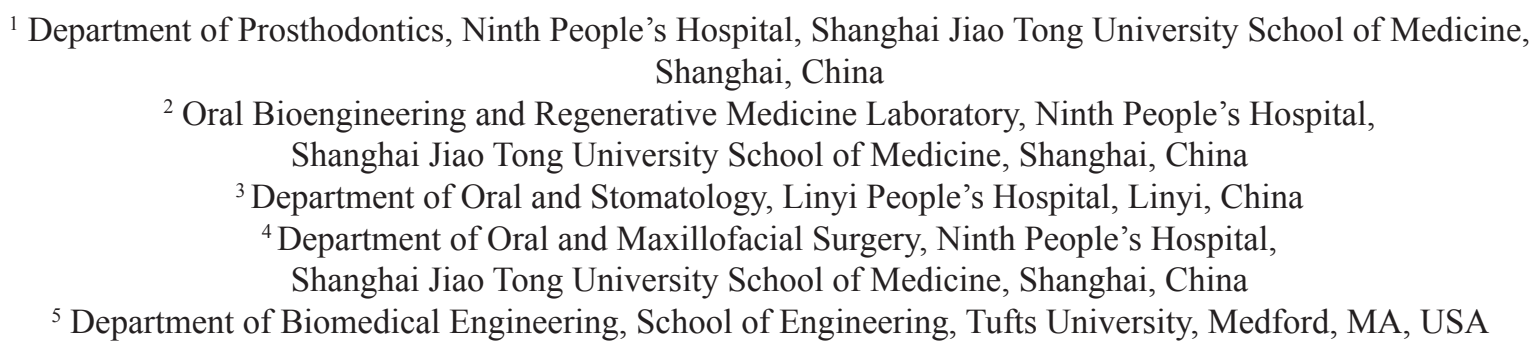

\#These authors contributed equally.

\begin{abstract}
Vascular endothelial growth factor (VEGF) and bone morphogenetic protein-2 (BMP-2) have been widely used in the fields of tissue engineering and regenerative medicine to stimulate angiogenesis and bone formation. The goal of this study was to determine whether VEGF and BMP-2 are involved in the homing of bone marrow stem cells (BMSCs) for bone regeneration and to provide insights into their mechanism of action. The chemoattraction of BMSCs to VEGF and BMP-2 was analysed in vitro using a checkerboard assay. VEGF and BMP-2 stimulated the chemotaxis of BMSCs but not chemokinesis. In vivo, both VEGF and BMP-2 also have been confirmed to induce the homing of tail vein injected BMSCs to the site of silk scaffold subcutaneous implantation in nude mice. When the scaffolds were implanted in the rabbit skull defects, more SSEA4+ mesenchymal stem cells were mobilised and homed to silk scaffolds containing VEGF and/or BMP-2. More importantly, autogenic BMSCs were reinjected via the ear vein after labelling with lenti-GFP, and the cells were detected to home to the defects and differentiate into endothelial cells and osteogenic cells induced by VEGF and BMP-2. Finally, perfusion with Microfil showed that initial angiogenesis was enhanced in tissue-engineered complexes containing VEGF. Observations based on $\mu \mathrm{CT}$ assay and histological study revealed that bone formation was accelerated on BMP-2-containing scaffolds. These findings support our hypothesis that the localised release of VEGF and BMP-2 promote bone regeneration, in part by facilitating the mobilisation of endogenous stem cells and directing the differentiation of these cells into endothelial and osteogenic lineages.
\end{abstract}

Keywords: Cell homing; stem cells; silk fibroin; VEGF; BMP-2; bone regeneration.

*Addresses for correspondence:

Dr Xinquan Jiang

Ninth People's Hospital

Shanghai Jiao Tong University, School of Medicine

639 Zhizaoju Road, Shanghai, 200011, China.

Telephone Number: +862163135412

FAX Number: +862163136856

E-mail: xinquanj@aliyun.com
Dr David L. Kaplan

School of Engineering, Tufts University

4 Colby St, Medford, MA 02155, USA

Telephone Number: +16176273251

FAX Number: +1 6176273231

E-mail: david.kaplan@tufts.edu

\section{Introduction}

Cell-based tissue engineering strategies have been adopted to promote tissue regeneration; however, exogenous cell delivery has many disadvantages, including the potential for pathogen transmission or tumourigenesis, complex operation procedures, high costs and extended regulatory approval processes. An alternative to cell-based tissue regeneration is to recruit endogenous cells (Chen et al., 2011; Discher et al., 2009; Kim et al., 2010; Lee et al., 2010). In addition, it has become apparent that cells seeded on biomaterial matrices usually do not survive for long in vivo but can secrete proteins to recruit endogenous cells that promote tissue regeneration (Vogel, 2011). Recently, scaffolds containing stromal derived factor- 1 (SDF-1), transforming growth factor- $\beta$ (TGF- $\beta$ ) and other cytokines have been used to recruit endogenous stem cells to improve healing and promote tissue regeneration (Kim et al., 2010; Lee et al., 2010; Thevenot et al., 2010). Stem cell therapy shows tremendous value for many serious diseases and injuries. However, to facilitate clinical translation, combinations of cell-free scaffolds and growth factors must be developed to provide a simpler and more convenient strategy to direct the homing of endogenous cells (Chen et al., 2011; Lee et al., 2010; Sackstein et al., 2008).

Scaffolds alone do not usually completely heal the defects due to the lack of sufficient osteoinduction. The incorporation of osteoinductive factors into scaffolds is usually required to promote sufficient bone regeneration (Chin et al., 2005; Li et al., 2011; Liu et al., 2009). Specific growth factors play important roles in the regeneration process of different tissues (James et al., 2011; Lee et al., 2011; Sood et al., 2012). Bone is a highly vascularised tissue in which blood vessels and bone cells interact to maintain skeletal integrity (Jiang, 2012; Kanczler and Oreffo, 2008; Zou et al., 2011). Therefore, 
(a)

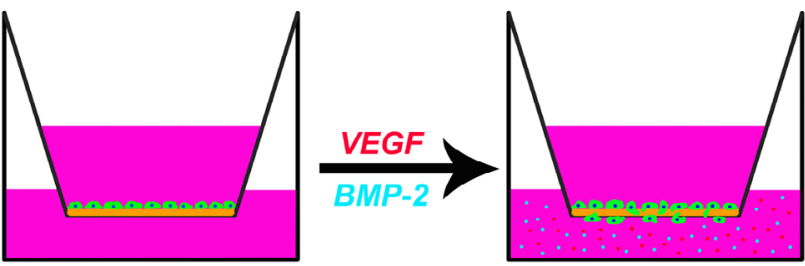

(b)

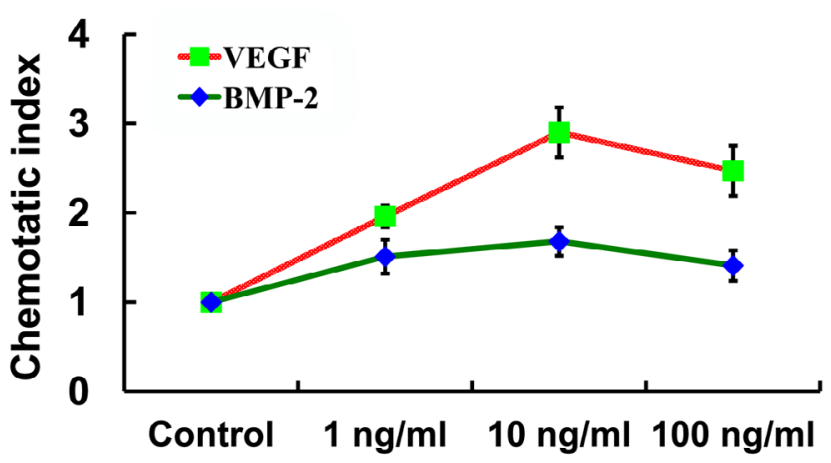

(C)
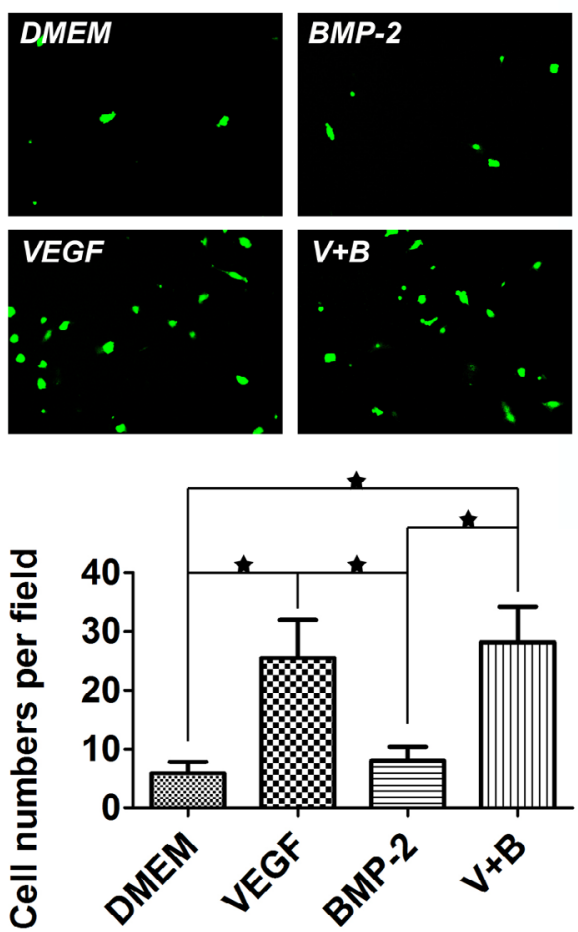

Fig. 1. (a) Schematic of the transwell chemotaxis model. (b) Dose-response curve of chemotactic migration activity of rabbit BMMSCs to VEGF and BMP-2. Chemotactic index of three independent experiments are shown as mean \pm standard deviation. (c) BMSCs adherent to the underside of the transwells were visualised by fluorescent microscopy, and cell migration to the underside of the chamber were quantified by cell counting ( $\star$, represents $p<0.05$ ).

angiogenesis and osteogenesis are both important for bone regeneration. Vascular endothelial growth factor (VEGF) and bone morphogenetic protein-2 (BMP-2) are two key regulators of angiogenesis and osteogenesis and promote the endothelial and osteogenic differentiation of stem cells, respectively. These two factors synergistically enhance bone regeneration (Lin et al., 2010; Peng et al., 2005; Samee et al., 2008). Our recent work confirms that combinations of VEGF and BMP-2 have additive effects on bone regeneration (Zhang et al., 2011). However, there is still no direct evidence regarding the mechanism of action of these two factors on stem cell homing and differentiation during bone regeneration. Based on our previous observations that combinations of VEGF and BMP-2 promote tissue ingrowth into silk gels as well as angiogenesis and bone regeneration in the elevated sinus cavity (Zhang et al., 2011), we hypothesise that the localised release of VEGF and BMP-2 facilitates the homing of endogenous cells, including bone marrow stem cells (BMSCs). We further hypothesise that VEGF and BMP-2 direct these homing cells to differentiate into endothelial cells and osteogenic cells at the regeneration site.

To test these hypotheses, porous silk protein scaffolds loaded with VEGF and BMP-2 were implanted in rabbit calvarial defects. At an early stage after implantation, endogenous stem cells recruited to the bone defects were identified by SSEA-4 immunoreactivity. Autogenic
BMSCs were isolated and labelled with lenti-GFP, and then reinjected via the ear vein for cell tracing to determine whether VEGF and BMP-2 can attract these cells homing and direct their differentiation.

\section{Materials and Methods}

\section{BMSC isolation and culture}

Rabbit BMSCs were obtained as previously described (Jiang et al., 2009a). Rabbits were placed under general anaesthesia through the intramuscular injection of ketamine $(40 \mathrm{mg} / \mathrm{kg}), 3 \mathrm{~mL}$ of bone marrow was harvested from their fibulae, and the bone marrow was cultured in Dulbecco's modified Eagle medium (DMEM) (Gibco, Grand Island, NY, USA) containing $10 \%$ foetal bovine serum (Hyclone, Logan, UT, USA). Non-adherent cells were removed after $5 \mathrm{~d}$ incubation. Cells were sub-cultured using $0.25 \%$ trypsin/EDTA until the cell density reached approximately $80 \%$ confluence.

\section{VEGF and BMP-2 effects on BMSC chemotaxis}

The transwell chemotactic migration model (Fig. 1a) was used to evaluate the recruitment capacity of VEGF and BMP-2 on BMSCs in vitro (Thevenot et al., 2010). Briefly, BMSCs were labelled with green fluorescent protein (GFP) by lentivirus transfection, as previously described (Zhu et al., 2011). These GFP-labelled BMSCs were suspended in 
DMEM and seeded in the upper chambers of $8 \mu \mathrm{m}$ pore membranes of 24-well plates (Corning Costar, Oneonta, NY, USA). In the lower chambers, different media were added in the following four groups: (a) DMEM; (b) DMEM containing $6 \mathrm{ng} / \mathrm{mL}$ recombinant human VEGF (gift from Wyeth); (c) DMEM containing $10 \mathrm{ng} / \mathrm{mL}$ recombinant human BMP-2 (gift from Wyeth); and (d) DMEM containing $6 \mathrm{ng} / \mathrm{mL}$ VEGF and $10 \mathrm{ng} / \mathrm{mL}$ BMP2 . The upper chambers were fixed and observed under the fluorescence microscope after $24 \mathrm{~h}$ culture. Six separate wells for each group were used in this experiment $(n=6)$. Five high power fields (HPF) were selected randomly in each well to count cell numbers.

The checkerboard assay was further carried out to assess chemotactic activity as previously described (Kim and Broxmeyer, 1998; Lind et al., 1996). Four growth factor concentrations $(0,1,10$ and $100 \mathrm{ng} / \mathrm{mL})$ were selected and used in this experiment. First, $2.0 \times 10^{5}$ cells were added to the upper well of the chamber. After incubation for $5 \mathrm{~h}$ at $37^{\circ} \mathrm{C}$ with $5 \% \mathrm{CO}_{2}$, cells migrating into the lower chamber were counted using the FACS Calibur flow cytometer (BD Biosciences, San Jose, CA, USA). The ratio of the number of migrated cells in the test well to the number of migrated cells in the control well $(0 \mathrm{ng} / \mathrm{mL}$ growth factor $)$ represents the chemotactic index. The data were plotted as the mean values plus/minus standard deviations for three independent experiments.

\section{Effects of VEGF and BMP-2 on BMSC recruitment in vivo}

Porous silk scaffolds (pore size 400-500 $\mu \mathrm{m}$, disk shaped, $5 \mathrm{~mm}$ in diameter and $2 \mathrm{~mm}$ thick) were prepared according to our previously published procedures (Nazarov et al., 2004). For growth factor loading, a $20 \mu \mathrm{L}$ solution was added to each scaffold according to previous water absorption tests. Four study groups were prepared: (a) silk scaffolds loaded with $20 \mu \mathrm{L}$ water as a blank control (Silk group); (b) silk scaffolds loaded with $6 \mu \mathrm{g}$ VEGF (VEGF group); (c) silk scaffolds loaded with $10 \mu \mathrm{g}$ BMP-2 (BMP-2 group); and (d) silk scaffolds loaded with $6 \mu \mathrm{g}$ VEGF and $10 \mu \mathrm{g}$ BMP-2 (V+B group). After $20 \mu \mathrm{L}$ of growth factor solution were added in the scaffolds, the samples were placed in $4{ }^{\circ} \mathrm{C}$ overnight, and then the redundant solutions were removed using absorbent paper.

In order to establish whether VEGF and BMP-2 release was effective at mobilising stem cells from the circulation, cell tracing by tail vein injection in nude mice was performed, as previously described (Lee et al., 2012). Scaffolds were firstly implanted in the subcutaneous cavity of the nude mice for $7 \mathrm{~d}$. And the mice were irradiated sub-lethally $1 \mathrm{~d}$ before cell transplantation. Finally, $200 \mu \mathrm{L}$ of the GFP-labelled rabbit BMSCs $\left(4.0 \times 10^{5}\right.$ cells $)$ were injected through the tail vein. Animals were sacrificed at $2 \mathrm{~d}$ after injection and the implants and surrounding tissue was embedded and frozen in Tissue-Tek OCT compound. A cryomicrotome was used to cut $5 \mu \mathrm{m}$-thick sections, which were then placed onto microscope slides. All slides were stained with DAPI (Invitrogen, Carlsbad, CA, USA) before being observed under a confocal laser scanning microscope (CLSM) (Leica, Nusseloch, Germany).

\section{Rabbit cranial defects model}

A total of 20 male New Zealand white rabbits weighing between $2.5 \mathrm{~kg}$ and $3 \mathrm{~kg}$ were obtained from the Ninth People's Hospital Animal Centre (Shanghai, China). The experimental protocol was approved by the Animal Care and Experiment Committee of the Ninth People's Hospital. Four cranial defects were generated according to our previously reported model (Oktay et al., 2010). Briefly, a scalp incision was made under general anaesthesia, and the cranium was exposed by elevating both the skin and the periosteum. Four circular critical-sized defects were formed using a $5 \mathrm{~mm}$ diameter trephine bur. Silk scaffolds from the different study groups were placed in a specific order (Fig. 2). The cylinder model in the upper right of Fig. 2 shows the location used for the subsequent histological analysis (labelled in blue).

\section{Identification of initial stem cell recruitment}

Three rabbits were sacrificed one week after the operation, and the scaffolds were harvested and rapidly frozen to approximately $-30{ }^{\circ} \mathrm{C}$. The samples were embedded in Tissue-Tek OCT compound and $5 \mu \mathrm{m}$-thick sections were cut using a cryomicrotome. For immunofluorescence staining, the slides were immersed in phosphate-buffered saline (PBS) for $20 \mathrm{~min}$ to remove the OCT. Next, the sections were blocked with $10 \%$ goat serum for $30 \mathrm{~min}$ at room temperature. The treated sections were subsequently incubated with specific antibodies for $1 \mathrm{~h}$ at $37^{\circ} \mathrm{C}$. SSEA-4 was used to identify mesenchymal stem cells (MSCs) that had migrated to the defect (Gang et al., 2007; Thevenot et al., 2010). FITC-conjugated anti-mouse IgG antibody (BD Bioscience) was used as secondary antibody. All slides were counterstained with DAPI (Invitrogen). Fluorescence images were captured by the CLSM.

\section{Analysis of angiogenesis in early implants}

To observe angiogenesis at early stages after implantation, six rabbits were sacrificed at week 4 and perfused with Microfil (Flow Tech, Carver, MA, USA), as previously described (Zhang et al., 2011). Briefly, a perfusion channel was built via the bilateral carotid arteries, and the blood was cleared in the craniofacial vessels using $200 \mathrm{~mL}$ heparinised saline. The blue Microfil solution was then perfused until the entire tongue turned blue. After polymerisation of the infused Microfil, the cranial defect samples were extracted and fixed in $10 \%$ buffered formaldehyde solution. The samples were dehydrated in a series of increasing concentrations of alcohol (from $25 \%$ to $100 \%$ ) and placed into dimethylbenzene to clear the tissue. Digital images were acquired using a camera (Nikon, Tokyo, Japan) and analysed semi-automatically with ImageJ software (Fuchs et al., 2009; Zou et al., 2012). Blue blood vessels were extracted from the background after automatic thresholding and labelled in red. The area corresponding to blood vessels in the $5 \mathrm{~mm}$-diameter defect region was then calculated. The samples were subsequently embedded in poly(methyl methacrylate) (PMMA) and cut into $150 \mu \mathrm{m}$-thick sections using a microtome (Leica). After being ground and polished to a thickness of approximately $100 \mu \mathrm{m}$, the specimens were stained with Van Gieson's picro-fuchsin (Zhang et al., 2011). 

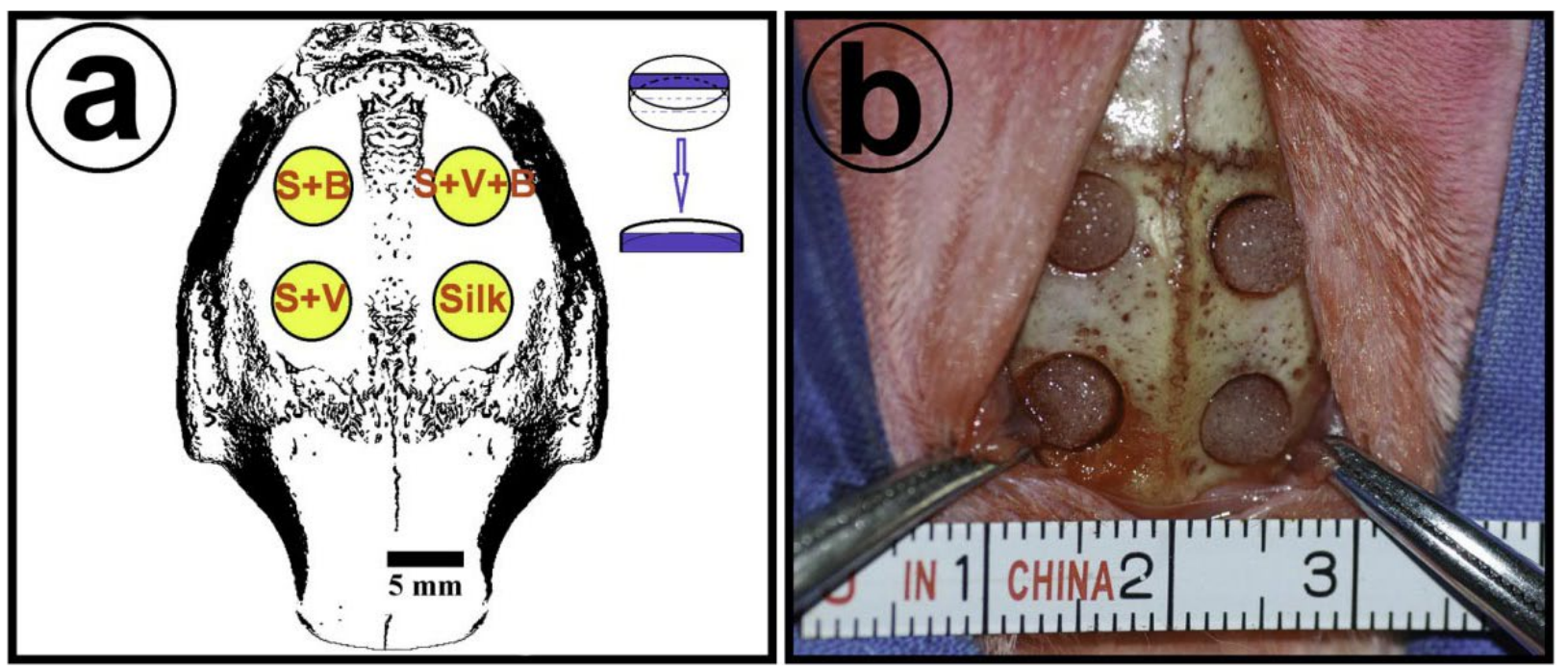

Fig. 2. (a) Schematic drawing of rabbit cranial bone defects. Four $5 \mathrm{~mm}$ (diameter) critical size defects were made on the skull for the implants. Cylinders on the upper right represent the silk scaffold, and the blue area shows the location where the tissue was taken for histological observation. (b) Rabbit cranium defects with silk scaffold-grafted.

\section{Bone regeneration analyses}

Eight rabbits were sacrificed at week 12 to compare osteogenesis in the different study groups. The following analyses were performed.

\section{Sequential fluorescent labelling}

The time course of new bone formation and mineralisation was recorded using a polychrome sequential fluorescent labelling method, as previously described (Jiang et al., 2009b; Wang et al., 2009). At 3, 6 and 9 weeks after the surgery, $25 \mathrm{mg} / \mathrm{kg}$ tetracycline hydrochloride (TE, Sigma, St. Louis, MO, USA), $20 \mathrm{mg} / \mathrm{kg}$ calcein (CA, Sigma) and $30 \mathrm{mg} / \mathrm{kg}$ Alizarin Red S (AL, Sigma) were administered intraperitoneally.

\section{Radiography and $\mu$ CT analysis}

Specimens were harvested and fixed in $10 \%$ buffered formaldehyde solution. Samples were imaged using a desktop $\mu \mathrm{CT}$ system ( $\mu \mathrm{CT}-80$, Scanco Medical, Bassersdorf, Switzerland) in high-resolution scanning mode (pixel matrix, 1024×1024; voxel size, $20 \mu \mathrm{m}$; slice thickness, $20 \mu \mathrm{m}$ ), as previously described (Zhang et al., 2011). Cranial X-ray images were acquired before scanning. The percentage of newly formed bone area in the entire defect region was calculated based on the radiography images using ImageJ software. After scanning with the $\mu \mathrm{CT}$ system, three-dimensional (3D) images were reconstructed using the Analyze software package (Scanco Medical). To evaluate the quality of the new bone, a cubic region of approximately $3.5 \mathrm{~mm} \times 3.5 \mathrm{~mm} \times 1 \mathrm{~mm}$ in the defect region was analysed. Bone volume (BV), bone volume fraction (BVF), tissue mineral content (TMC) and trabecular number $(\mathrm{TbN})$ were determined.

\section{Histological and histomorphometric observations}

Eight specimens from each group were bisected along their diameter. One half were decalcified, embedded in paraffin, cut into $4 \mu \mathrm{m}$-thick sections and stained with haematoxylineosin (HE). The other half were dehydrated, embedded in PMMA, sectioned into $150 \mu \mathrm{m}$-thick sections and ground and polished to a final thickness of approximately $40 \mu \mathrm{m}$. The undecalcified sections were used to observe sequential fluorescent labelling with CLSM. The excitation/ emission wavelengths were 405/580 nm for TE (yellow), 488/517 nm for CA (green) and 543/617 nm for AL (red). The undecalcified sections were further stained with Van Gieson's picro-fuchsin.

\section{Cell tracing in rabbit}

Experiments on the other three rabbits (Fig. 6a) were carried out to confirm the effects of VEGF and BMP-2 on BMSC recruitment and differentiation. Autogenic BMSCs were isolated and labelled with lenti-GFP in vitro. Four defects were made on the skull and implanted with the silk scaffolds as mentioned above. Then, $1 \mathrm{~mL}$ of the GFP-labelled rabbit BMSCs $\left(2.0 \times 10^{6}\right.$ cells $)$ were reinjected to the circulation via the ear vein at $3 \mathrm{~d}, 1$ week and 2 weeks after implantation, respectively. All animals were sacrificed at week 4 , and the samples were extracted and fixed in $4 \%$ paraformaldehyde solution for $30 \mathrm{~min}$. The samples were stained with DAPI before being observed under a fluorescence microscope. The samples were then decalcified in $15 \%$ EDTA and embedded in paraffin. Sections were made for immunohistochemical detection. After removal of paraffin and rehydration, sections were incubated with primary antibody against GFP (1:400 dilution; Abcam, Cambridge, UK). HRP-labelled secondary antibody and DAB substrate were sequentially added to detect the GFP+ cells in the specimens. Cell nuclei were slightly counterstained with haematoxylin.

\section{Statistical analysis}

Statistically significant differences $(p<0.05)$ among the various groups were measured using a one-way ANOVA 
Table 1. Checkerboard analysis of response of BMSCs to VEGF and BMP-2.

\begin{tabular}{|c|c|c|c|c|}
\hline \multirow{2}{*}{$\begin{array}{c}\text { VEGF concentration (ng/mL) } \\
\text { in Lower Chamber }\end{array}$} & \multicolumn{4}{|c|}{ VEGF concentration (ng/mL) in Upper Chamber } \\
\cline { 2 - 5 } $\mathbf{0}$ & $\mathbf{0}$ & $\mathbf{1}$ & $\mathbf{1 0}$ & $\mathbf{1 0 0}$ \\
\hline $\mathbf{1}$ & 1 & $0.71 \pm 0.01$ & $0.53 \pm 0.07$ & $0.56 \pm 0.07$ \\
\hline $\mathbf{1 0}$ & $1.96 \pm 0.12$ & $1.08 \pm 0.11$ & $0.85 \pm 0.05$ & $0.82 \pm 0.09$ \\
\hline $\mathbf{1 0 0}$ & $2.9 \pm 0.28$ & $1.48 \pm 0.06$ & $0.95 \pm 0.14$ & $0.94 \pm 0.05$ \\
\hline $\mathbf{n}$ & $2.47 \pm 0.28$ & $1.98 \pm 0.09$ & $1.55 \pm 0.16$ & $1.11 \pm 0.15$ \\
\hline \multirow{2}{*}{$\begin{array}{c}\text { BMP-2 concentration (ng/mL) } \\
\text { in Lower Chamber }\end{array}$} & $\mathbf{B M P - 2}$ concentration (ng/mL) in Upper Chamber \\
\cline { 2 - 5 } & $\mathbf{0}$ & $\mathbf{1}$ & $\mathbf{1 0}$ & $\mathbf{1 0 0}$ \\
\hline $\mathbf{0}$ & 1 & $0.85 \pm 0.08$ & $0.72 \pm 0.12$ & $0.67 \pm 0.01$ \\
\hline $\mathbf{1 0}$ & $1.51 \pm 0.19$ & $0.98 \pm 0.03$ & $0.76 \pm 0.01$ & $0.71 \pm 0.09$ \\
\hline $\mathbf{1 0 0}$ & $1.68 \pm 0.16$ & $1.23 \pm 0.04$ & $1.03 \pm 0.17$ & $0.83 \pm 0.09$ \\
\hline & $1.41 \pm 0.17$ & $1.38 \pm 0.08$ & $1.15 \pm 0.05$ & $0.91 \pm 0.08$ \\
\hline
\end{tabular}

followed by Tukey's post hoc test. All calculations were performed using a SAS 8.2 statistical software package.

\section{Results}

\section{Chemotactic activity of VEGF and BMP-2 on rabbit BMSCs in vitro}

The checkerboard assay was carried out to evaluate and clarify the chemotactic or chemokinetic activities of VEGF and BMP-2 on rabbit BMSCs. As shown in Table 1 , the chemokinetic index demonstrated that the effects of both VEGF and BMP-2 were primarily chemotactic. The dose-response curves (Fig. 1b) for VEGF- and BMP-2-mediated cell responses were bell shaped, and the maximum response for both proteins was observed at $10 \mathrm{ng} / \mathrm{mL}$ : the chemokinetic index values were $2.9 \pm 0.28$ for VEGF and $1.68 \pm 0.16$ for BMP-2. When VEGF and BMP-2 were added into the lower chambers for $24 \mathrm{~h}$, two groups containing VEGF recruited more GFP-labelled BMSCs than the other two groups $(p<0.05)$. Although there was no significant difference between the two groups in the present experiment, the recruited cell number in the BMP-2 group was slightly higher than in the control group. (Fig. 1c).

\section{Effects of VEGF and BMP-2 on rabbit BMSC recruitment in vivo}

Homing of intravenous. transplanted rabbit BMSCs in the nude mouse model was taken to establish whether VEGF and BMP-2 release was effective at mobilising stem cells from the circulation. Quantification of these responses on the basis of cell number reveals significant increase in the three groups containing growth factors (Fig. 3). In addition, the numbers of the recruited GFP-labelled BMSCs in the two groups containing VEGF were significantly higher than that in the BMP-2 group $(p<0.05)$.

\section{Effects of VEGF and BMP-2 on MSC recruitment in rabbit}

To assess whether VEGF and BMP-2 promoted stem cell mobilisation and migration into the silk scaffolds in rabbit, samples implanted in the cranial defects were extracted after one week and analysed. Silk scaffolds loaded with VEGF, BMP-2 or both factors attracted more MSCs (SSEA-4-positive) than the scaffolds without growth factors (Fig. 4).

\section{Neo-angiogenesis in early defects}

Blood vessels filled with blue Microfil were clearly visible in the specimens from week 4. A higher density of newly formed blood vessels was found in the VEGF and $\mathrm{V}+\mathrm{B}$ groups than the other two groups (Fig. 5a). The lowest number of vessels was found in the Silk group. The blood vessel area was calculated (Fig. 6b). The VEGF group and the $\mathrm{V}+\mathrm{B}$ group had blood vessel areas of $5.43 \pm 0.41 \mathrm{~mm}^{2}$ and $5.57 \pm 0.37 \mathrm{~mm}^{2}$, respectively. Both groups had significantly larger areas than the Silk group and the BMP-2 group. There was no significant difference between the VEGF group and $\mathrm{V}+\mathrm{B}$ group. In addition, the blood vessel area in the BMP-2 group $\left(4.12 \pm 0.32 \mathrm{~mm}^{2}\right)$ was significantly larger than that of the Silk group $\left(2.49 \pm 0.39 \mathrm{~mm}^{2}\right)$.

\section{New bone formation in the defects}

Three-dimensional images of the newly formed bone were reconstructed by $\mu \mathrm{CT}$ (Fig. $5 \mathrm{c}$ ). Bone repair in the $\mathrm{V}+\mathrm{B}$ group was significantly greater than in the other three study groups. Tissue from cubic defect regions of approximately $3.5 \mathrm{~mm} \times 3.5 \mathrm{~mm} \times 1 \mathrm{~mm}$ was selected to evaluate the quality of the new bone. Bone volume, bone volume fraction, tissue mineral content and trabecular number were measured (Table 2). In the $\mathrm{V}+\mathrm{B}$ group, the bone volume was $5.66 \pm 1.08 \mathrm{~mm}^{3}$, the bone volume fraction was $0.36 \pm 0.07$, the tissue mineral content was $3.24 \pm 0.69 \mathrm{mg}$, and the trabecular number was $2.44 \pm 0.23$. All of these data were significantly higher compared with the other three study groups. In addition, X-ray images were taken to observe the area of newly formed bone in the defects (Fig. 5d). The percentage of new bone area in the $\mathrm{V}+\mathrm{B}$ group was $91.39 \pm 6.87 \%$, which was significantly higher than the Silk group $(27.87 \pm 6.80 \%)$, VEGF group $(43.71 \pm 9.40 \%)$ and BMP-2 group $(76.79 \pm 5.08 \%)$. The histological analysis further supported the results of $\mu \mathrm{CT}$ 


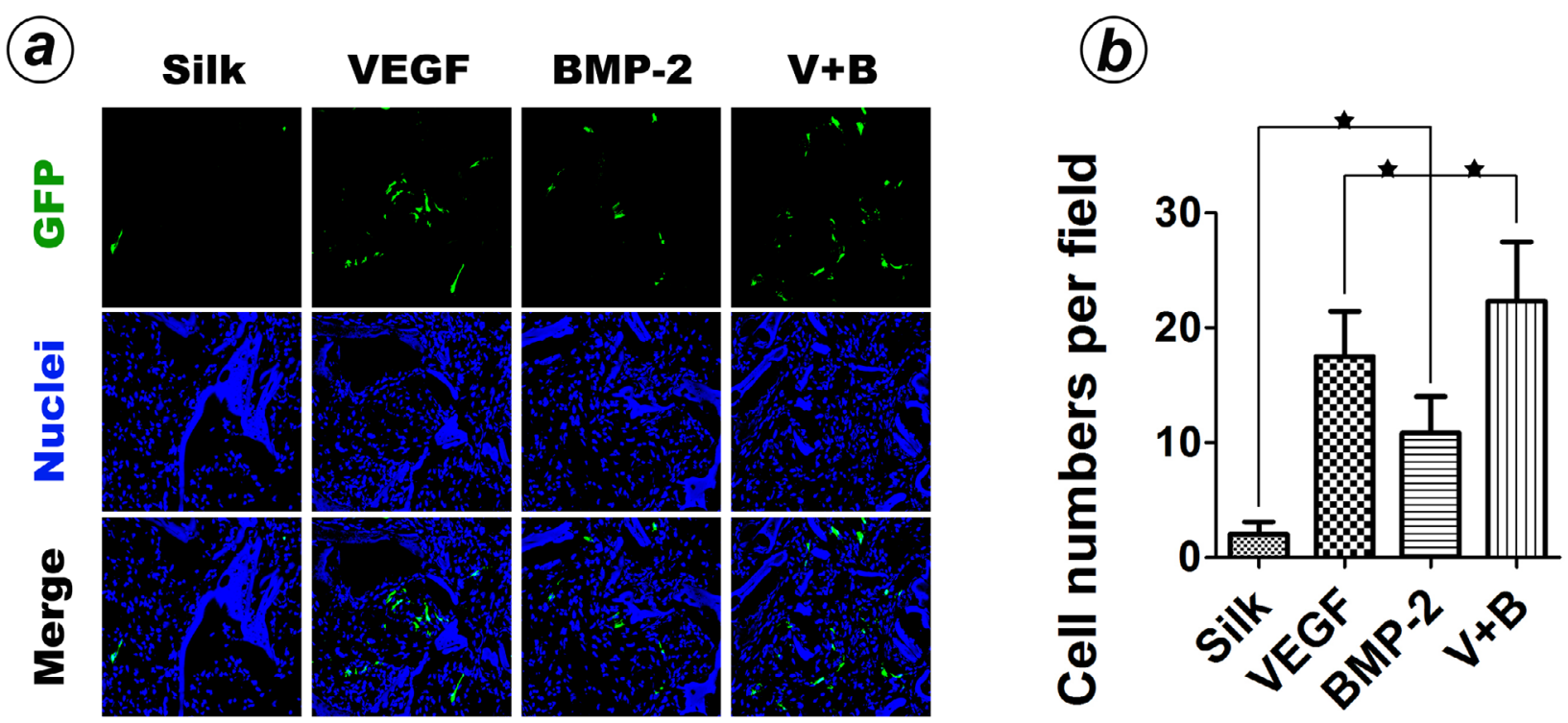

Fig. 3. (a) VEGF and BMP-2 increases engraftment of BMSCs (GFP+) to subcutaneously implanted silk scaffolds. (b) The density of BMSCs in the scaffold interior was quantified between groups by cell counting ( $\star$, represents $p<0.05)$.

\section{(a) SSEA-4/DAPI}
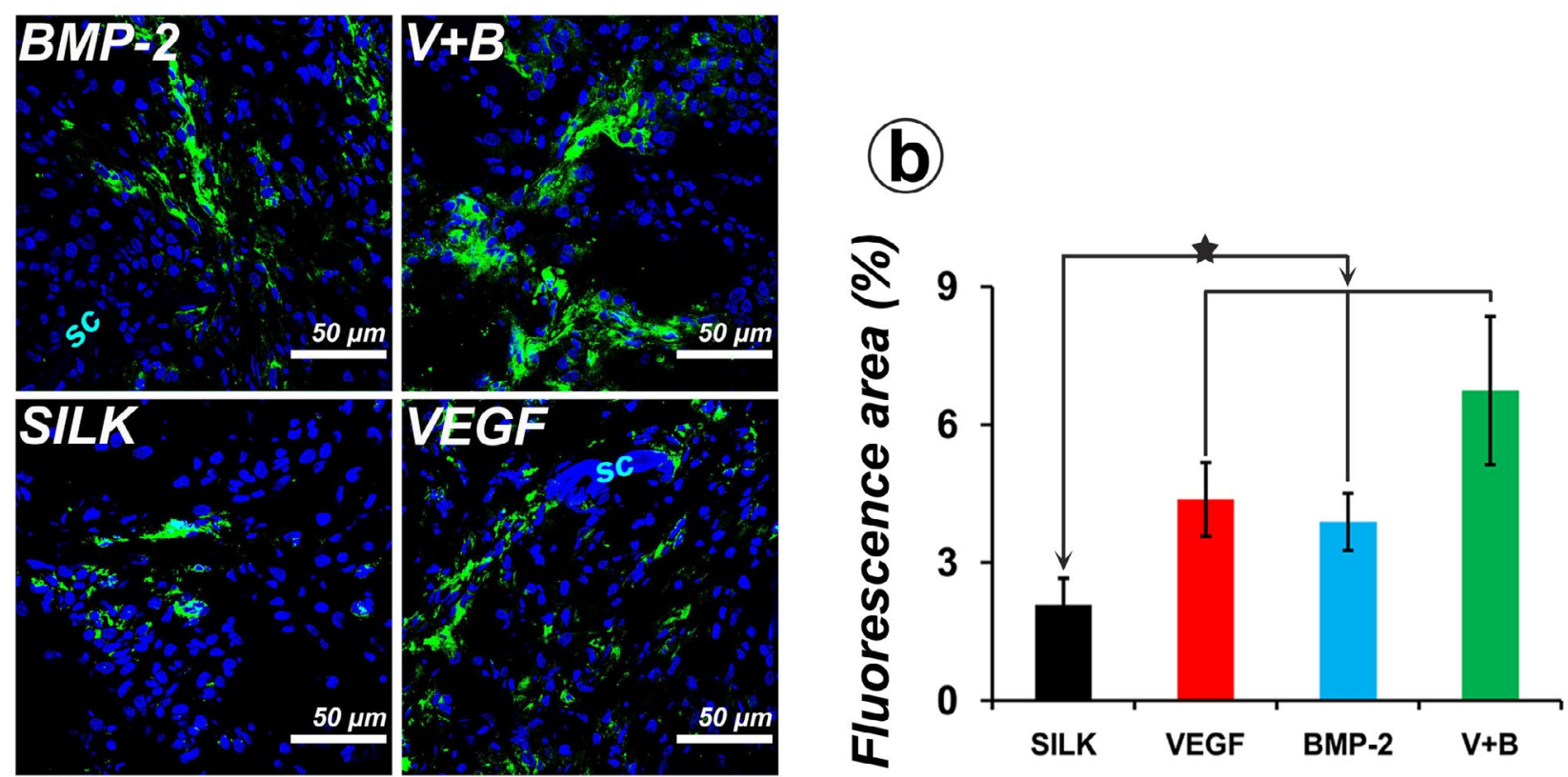

Fig. 4. Samples implanted in rabbit cranial defects for one week. (a) Immunofluoresence observation for SSEA-4 (green area represents FITC-labelled SSEA-4, and blue area represents DAPI-stained nuclei). (b) The percent of SSEA-4-positive areas in the observed field were calculated $(\star$, represents $p<0.05)$.

Table 2. Quantitative results of the $\mu \mathrm{CT}$ evaluation.

\begin{tabular}{|l|c|c|c|c|}
\hline \multirow{2}{*}{ Parameters } & Silk & VEGF & BMP-2 & V+B \\
\cline { 2 - 5 } BV $\left(\mathbf{m m}^{\mathbf{3}}\right)$ & $0.64 \pm 0.19$ & $1.54 \pm 0.25$ & $3.79 \pm 0.71$ & $5.66 \pm 1.08 *$ \\
\hline BV/TV (\%) & $4.12 \pm 1.23$ & $10.14 \pm 1.66$ & $24.55 \pm 4.92$ & $35.62 \pm 6.78 *$ \\
\hline TMC (mg) & $0.39 \pm 0.13$ & $0.86 \pm 0.13$ & $2.12 \pm 0.40$ & $3.24 \pm 0.69 *$ \\
\hline Tb.N (mm $\left.\mathbf{~ m}^{-1}\right)$ & $0.11 \pm 0.04$ & $0.76 \pm 0.20$ & $1.93 \pm 0.23$ & $2.44 \pm 0.23 *$ \\
\hline
\end{tabular}

Data were expressed as mean \pm standard deviation $(n=8) .{ }^{*}, p<0.05$ when compared with the other three groups. 

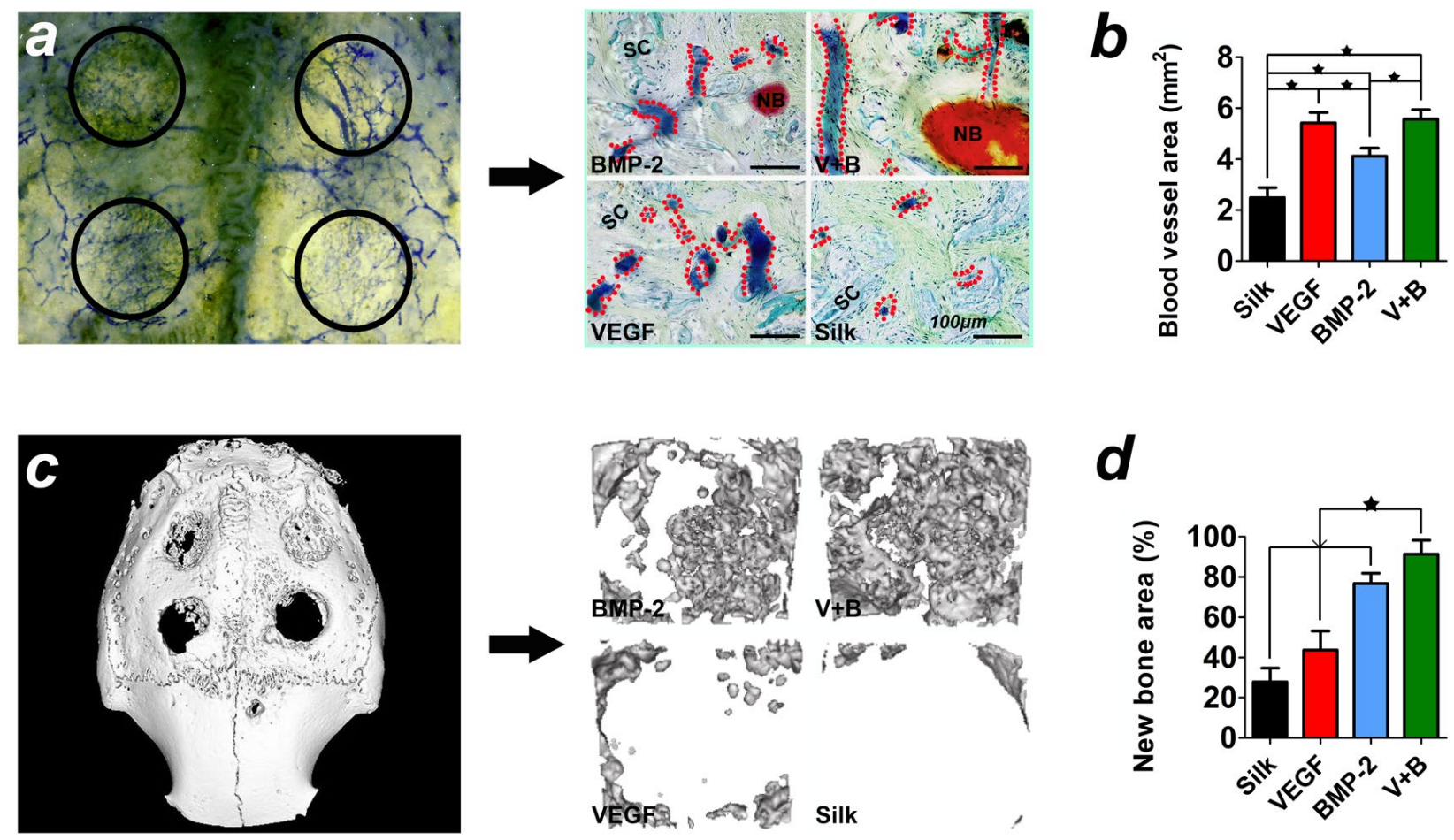

e

\section{Silk}

VEGF

BMP-2

$V+B$
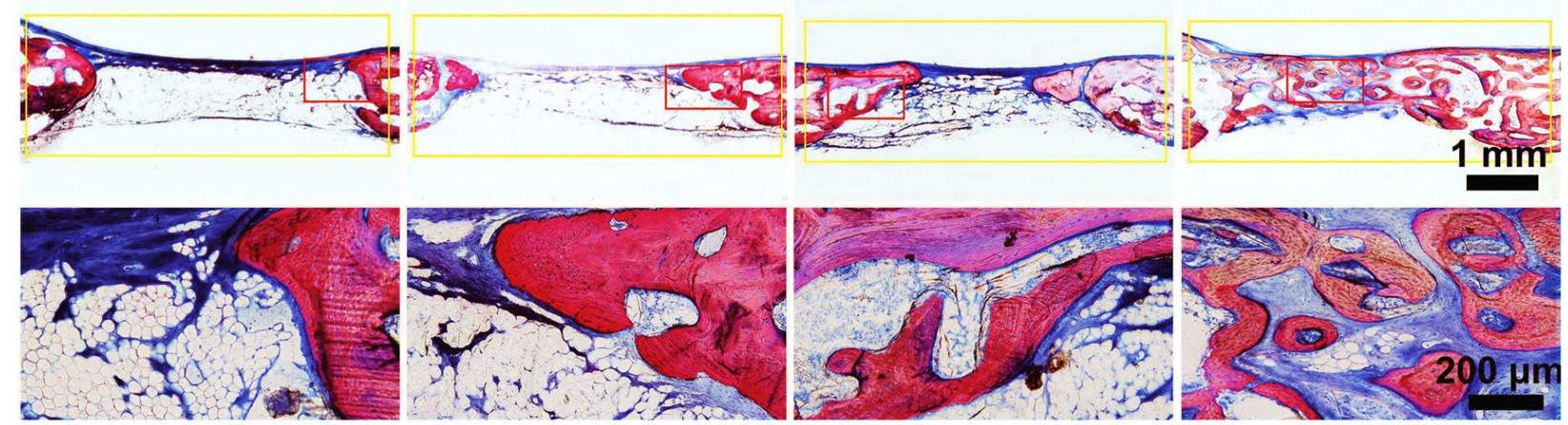

Fig. 5. (a) Neo-angiogenesis detection at week 4. Observation of blood vessels (labelled with blue coloured Microfil) in the gross specimens, and histological observation on the undecalcified sections (red dash lines surround the blood vessels, $\mathrm{SC}=$ scaffold, $\mathrm{NB}=$ new bone). (b) Analysis of the local vessel area in the defects. (c) New bone formation at 12 weeks after implantation. The apical and antapical views of three-dimensional reconstruction image. Cubic regions about $3.5 \mathrm{~mm} \times 3.5 \mathrm{~mm} \times 1 \mathrm{~mm}$ within the defects were selected to evaluate the quality of new bone. (d) The graph shows the percentage of new bone area in the different groups. (e) Undecalcified sections were stained with Van Gieson's picro fuchsin. The large yellow rectangles show the location of the critical sized defects. Partial magnifications of the small red rectangle area are displayed in the lower panel ( $\star$, represents $p<0.05$ ).

measurements (Fig. 5e). The most robust bone formation occurred in the $\mathrm{V}+\mathrm{B}$ group, with less bone formation occurring in the BMP-2 group and VEGF group and no obvious bone formation in the Silk scaffold group.

\section{VEGF and BMP-2 induced BMSC homing and differentiation}

Experiments on BMSC tracing were performed to confirm whether VEGF and BMP-2 could facilitate the mobilisation of stem cells and directing the differentiation of these cells into endothelial and osteogenic lineages. As shown in Fig. 6c, more GFP-positive cells were observed in the two groups loaded with VEGF, which is consistent with BMSC recruitment results in nude mice. The scaffolds containing BMP-2 attracted less injected cells, but the $\mathrm{GFP}+$ cell number was still higher than that in the control group. Furthermore, in the $\mathrm{V}+\mathrm{B}$ group, we detected the GFP+ BMSCs on the paraffin sections using the immunohistochemical method. Some of the positive cells were found to locate at newly formed bone and vessels, which might indicate that VEGF and BMP-2 can induce endogenous stem cell homing and differentiation into endothelial and osteogenic lineages. 
(a)
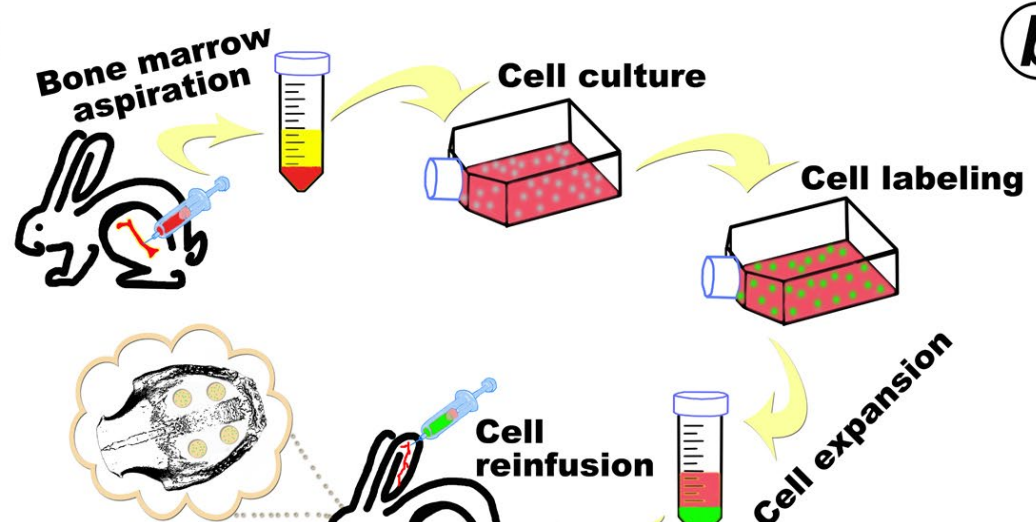

Calvarial defects

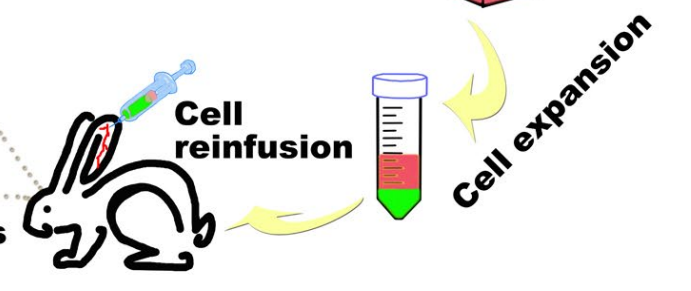

(b)

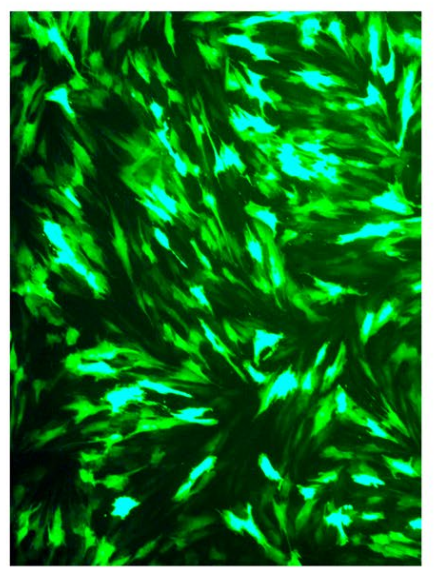

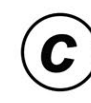

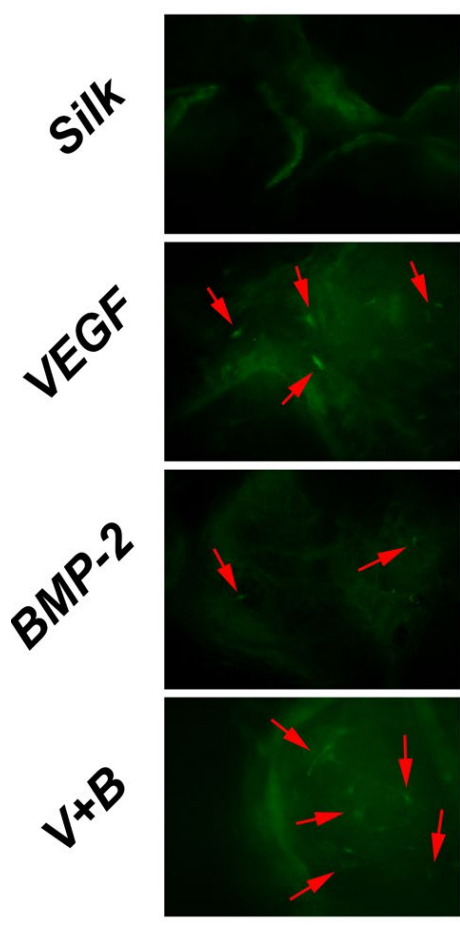

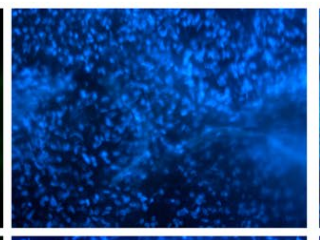
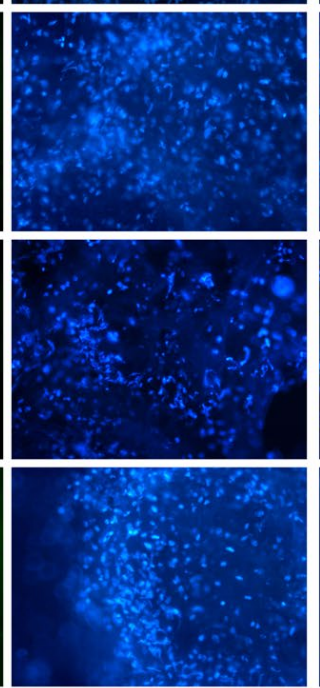

Fig. 6. (a) Experimental protocol for cell tracing in rabbits. (b) Rabbit BMSCs labelled with lenti-GFP. (c) VEGF and BMP-2 increases engraftment of BMSCs (GFP+) to the scaffolds implanted in rabbit cranial defects for 4 weeks. (d) Immunostaining for GFP in V+B group. GFP positive cells stained brownish yellow (red arrows).

\section{Discussion}

The combination of VEGF and BMP-2 has been documented for its effects on angiogenesis and osteogenesis (Kanczler et al., 2010; Peng et al., 2005; Young et al., 2009). VEGF stimulates the formation of supportive vascular networks, which enhance the bone formation effects of BMP-2 (Kempen et al., 2009). In addition, it is interesting to note that VEGF can also serve as a mobilisation cytokine for endothelial progenitor cells that promote bone regeneration (Lee et al., 2008). In the present study, we further investigated the roles of VEGF and BMP-2 as cell homing molecules that induce endogenous stem cell recruitment. Because bone marrow is a major source of MSCs that home to injured organs through the bloodstream (Chen et al., 2011), we selected rabbit BMSCs for use in transwell chemotaxis experiments and in vivo homing experiments. Interestingly, both VEGF and BMP-2, especially VEGF, stimulated the chemotactic migration of rabbit BMSCs in the checkerboard assay. More importantly, the effects of VEGF and BMP-2 on BMSC homing were further confirmed in the nude mouse model.

To evaluate the homing capacity of these factors on endogenous stem cells in rabbit, we created four defects in 
one cranium for the implantation of four different scaffold types. One week later, the implants were extracted and analysed for the recruitment of stem cells. Consistent with the results in the nude mouse model, the SSEA-4positive MSC ratio in the Silk group was lower than the other three study groups containing growth factors. Cells from the neighbouring tissue rapidly migrated into the silk scaffolds to fill the defects after implantation. These migratory cells comprised large numbers of inflammatory or fibroblastic cells (similar to wound healing) but few MSCs. This initial migration process was caused by the wound response from the defect site, the physiological function of the cells, and the biocompatibility of the implant. In addition, MSCs from the bone marrow or other parts of the body are triggered by the defect sites and enter the circulation. The mobilisation of these MSCs may be correlated with the local concentration of cytokines (Chen et al., 2011). In this study, VEGF and BMP-2 released from silk scaffolds after implantation would have played a major role in the mobilisation of SSEA-4-positive cells. In the specimens collected one week after implantation, more CD31+ endothelial cells were observed in groups with VEGF, and more osterix-positive osteogenic cells were observed in groups with BMP-2 (data not shown). Two possible mechanisms provide a reasonable explanation for these results. First, VEGF and BMP-2 might serve as inducible factors to stimulate the chemotactic migration of endothelial cells and osteogenic cells, respectively (Asahara et al., 1999; Hutchings et al., 2003; Lind et al., 1996). Second, the CD31+ and osterix-positive cells might derive from the homing MSCs that subsequently differentiate due to local VEGF and BMP-2 stimulation. In the present study, the findings that VEGF and BMP-2 induced the injected BMSC homing and differentiation appear to provide strong evidence for these presumptions.

VEGF and BMP-2 released from scaffolds can stimulate endothelial cell and osteoblast migration from neighbouring tissue (Asahara et al., 1999; Hutchings et al., 2003; Lind et al., 1996). VEGF and BMP-2 can also promote MSC homing and induce these stem cells to differentiate into endothelial and osteogenic cells. In addition, VEGF and BMP-2 also have cross-coupling effects on osteogenic differentiation and angiogenesis, respectively. VEGF promotes bone regeneration by not only promoting angiogenesis but also directly inducing the osteogenic differentiation of MSCs (Behr et al., 2011). This has been confirmed by culturing BMSCs in medium containing VEGF (data not shown). Accordingly, BMP-2 promotes angiogenesis by inducing osteoblast-derived VEGF expression or activating endothelial cells directly (Deckers et al., 2002; Langenfeld and Langenfeld, 2004; Raida et al., 2006). The analysis of angiogenesis in week 4 specimens and bone formation in week 12 specimens confirmed these findings. Based on these findings, we concluded that combined VEGF and BMP-2 treatment is a promising strategy for bone regeneration.

Revealing the mechanisms of VEGF and BMP-2 in bone regeneration will be important for directing future clinical applications. Appropriate scaffolds are another key factor that must be taken into consideration. Silk fibroin is recognised as a promising natural biomaterial for various clinical applications. Silk fibres have been used as medical sutures and are approved by the FDA (Altman et al., 2003; Omenetto and Kaplan, 2010; Tsioris et al., 2011). Silk scaffolds have also been used as drug delivery vehicles to repair bone defects (Karageorgiou et al., 2006; Kirker-Head et al., 2007). The porous silk scaffold used in the present study contains micropores in the range of 400-500 $\mu \mathrm{m}$, which facilitate tissue ingrowth. All of these features contribute to the impressive results of bone regeneration in our study. After twelve weeks in vivo, the silk scaffolds were hardly detectable and had been replaced by mature bone-like structures (data not shown). The tissue-engineered silk scaffold constructs containing VEGF and BMP-2 were easily prepared and can be made readily available for clinical bone repair. Silk fibroin can be fabricated into different forms and different shapes to adapt to many types of bone defects. We believe that these growth factor-loaded scaffolds will be a good choice for future clinical application due to their functionality and operability.

\section{Conclusions}

We provide evidence that VEGF and BMP-2 act as homing molecules to stimulate MSC homing and subsequently induce the differentiation of MSCs into endothelial and osteogenic cells. Porous silk scaffolds served as suitable matrix vehicles to release VEGF and BMP-2 in vivo and bone defects were repaired by promoting both angiogenesis and new bone formation. These findings suggest that combined treatment with VEGF and BMP-2 could be a promising strategy for clinical bone regeneration.

\section{Acknowledgments}

The authors thank Carmen Preda (Tufts University) for fabricating the silk scaffolds used in this study. This work was jointly supported by the National Basic Research Program of China (973 Program, 2012CB933604), the National Science Fund for Distinguished Young Scholars of China (No. 81225006), and the National Natural Science Foundation of China (No. 81170939). Dr. Jiang would like to acknowledge the Chang Jiang Scholars Programme of the Ministry of Education of China. We also thank the National Institutes of Health (DK) [DE017207, EB003210, EB002520, DE16710 and DE21464] for supporting this study.

\section{References}

Altman GH, Diaz F, Jakuba C, Calabro T, Horan RL, Chen J, Lu H, Richmond J, Kaplan DL (2003) Silk-based biomaterials. Biomaterials 24: 401-416.

Asahara T, Takahashi T, Masuda H, Kalka C, Chen D, Iwaguro H, Inai Y, Silver M, Isner JM (1999) VEGF contributes to postnatal neovascularization by mobilizing 
bone marrow-derived endothelial progenitor cells. EMBO J 18: 3964-3972.

Behr B, Tang C, Germann G, Longaker MT, Quarto N (2011) Locally applied vascular endothelial growth factor A increases the osteogenic healing capacity of human adipose-derived stem cells by promoting osteogenic and endothelial differentiation. Stem Cells 29: 286-296.

Chen FM, Wu LA, Zhang M, Zhang R, Sun HH (2011) Homing of endogenous stem/progenitor cells for in situ tissue regeneration: Promises, strategies, and translational perspectives. Biomaterials 32: 3189-3209.

Chin M, Ng T, Tom WK, Carstens M (2005) Repair of alveolar clefts with recombinant human bone morphogenetic protein (rhBMP-2) in patients with clefts. J Craniofac Surg 16: 778-789.

Deckers MML, van Bezooijen RL, van der Horst G, Hoogendam J, van der Bent C, Papapoulos SE, Löwik CWGM (2002) Bone morphogenetic proteins stimulate angiogenesis through osteoblast-derived vascular endothelial growth factor A. Endocrinology 143: 15451553.

Discher DE, Mooney DJ, Zandstra PW (2009) Growth factors, matrices, and forces combine and control stem cells. Science 324: 1673-1677.

Fuchs S, Jiang X, Schmidt H, Dohle E, Ghanaati S, Orth C, Hofmann A, Motta A, Migliaresi C, Kirkpatrick CJ (2009) Dynamic processes involved in the pre-vascularization of silk fibroin constructs for bone regeneration using outgrowth endothelial cells. Biomaterials 30: 1329-1338.

Gang EJ, Bosnakovski D, Figueiredo CA, Visser JW, Perlingeiro RC (2007) SSEA-4 identifies mesenchymal stem cells from bone marrow. Blood 109: 1743-1751.

Hutchings H, Ortega N, Plouët J (2003) Extracellular matrix-bound vascular endothelial growth factor promotes endothelial cell adhesion, migration, and survival through integrin ligation. FASEB J 17: 1520-1522.

James R, Kumbar S, Laurencin C, Balian G, Chhabra A (2011) Tendon tissue engineering: adipose-derived stem cell and GDF-5 mediated regeneration using electrospun matrix systems. Biomed Mater 6: 025011.

Jiang X (2012) On novel options for oromaxillofacial functional restoration. Int J Prosthodont 25: 132-134.

Jiang XQ, Sun XJ, Lai HC, Zhao J, Wang SY, Zhang ZY (2009) Maxillary sinus floor elevation using a tissueengineered bone complex with beta-TCP and BMP-2 gene-modified bMSCs in rabbits. Clin Oral Implants Res 20: 1333-1340.

Jiang XQ, Wang SY, Zhao J, Zhang XL, Zhang ZY (2009) Sequential fluorescent labeling observation of maxillary sinus augmentation by a tissue-engineered bone complex in canine model. Int J Oral Sci 1: 39-46.

Kanczler JM, Oreffo RO (2008) Osteogenesis and angiogenesis: the potential for engineering bone. Eur Cell Mater 15: 100-114.

Kanczler JM, Ginty PJ, White L, Clarke NM, Howdle SM, Shakesheff KM, Oreffo RO (2010) The effect of the delivery of vascular endothelial growth factor and bone morphogenic protein-2 to osteoprogenitor cell populations on bone formation. Biomaterials 31: 1242-1250.
Karageorgiou V, Tomkins M, Fajardo R, Meinel L, Snyder B, Wade K, Chen J, Vunjak-Novakovic G, Kaplan DL (2006) Porous silk fibroin 3-D scaffolds for delivery of bone morphogenetic protein-2 in vitro and in vivo. $\mathrm{J}$ Biomed Mater Res A 78: 324-334.

Kempen DH, Lu L, Heijink A, Hefferan TE, Creemers LB, Maran A, Yaszemski MJ, Dhert WJ (2009) Effect of local sequential VEGF and BMP-2 delivery on ectopic and orthotopic bone regeneration. Biomaterials 30: 2816-2825.

Kim CH, Broxmeyer HE (1998) In vitro behavior of hematopoietic progenitor cells under the influence of chemoattractants: stromal cell-derived factor-1, steel factor, and the bone marrow environment. Blood 91: 100110.

Kim K, Lee C, Kim B, Mao J (2010) Anatomically shaped tooth and periodontal regeneration by cell homing. J Dent Res 89: 842-847.

Kirker-Head C, Karageorgiou V, Hofmann S, Fajardo R, Betz O, Merkle HP, Hilbe M, von Rechenberg B, McCool J, Abrahamsen L, Nazarian A, Cory E, Curtis M, Kaplan D, Meinel L (2007) BMP-silk composite matrices heal critically sized femoral defects. Bone 41: 247-255.

Langenfeld EM, Langenfeld J (2004) Bone morphogenetic protein-2 stimulates angiogenesis in developing tumors. Mol Cancer Res 2: 141-149.

Lee DY, Cho TJ, Kim JA, Lee HR, Yoo WJ, Chung CY, Choi IH (2008) Mobilization of endothelial progenitor cells in fracture healing and distraction osteogenesis. Bone 42: 932-941.

Lee CH, Cook JL, Mendelson A, Moioli EK, Yao H, Mao JJ (2010) Regeneration of the articular surface of the rabbit synovial joint by cell homing: a proof of concept study. Lancet 376: 440-448.

Lee K, Silva EA, Mooney DJ (2011) Growth factor delivery-based tissue engineering: general approaches and a review of recent developments. J R Soc Interface 8: 153-170.

Lee J, Li M, Milwid J, Dunham J, Vinegoni C, Gorbatov R, Iwamoto Y, Wang F, Shen K, Hatfield K, Enger M, Shafiee S, McCormack E, Ebert BL, Weissleder R, Yarmush ML, Parekkadan B (2012) Implantable microenvironments to attract hematopoietic stem/cancer cells. Proc Natl Acad Sci USA 109: 19638-19643.

Li W, Zara JN, Siu RK, Lee M, Aghaloo T, Zhang X, Wu BM, Gertzman AA, Ting K, Soo C (2011) Nell-1 enhances bone regeneration in a rat critical-sized femoral segmental defect model. Plast Reconstr Surg 127: 580-587.

Lin CY, Chang YH, Lin KJ, Yen TC, Tai CL, Chen CY, Lo WH, Hsiao IT, Hu YC (2010) The healing of critical-sized femoral segmental bone defects in rabbits using baculovirus-engineered mesenchymal stem cells. Biomaterials 31: 3222-3230.

Lind M, Eriksen EF, Bünger C (1996) Bone morphogenetic protein-2 but not bone morphogenetic protein-4 and -6 stimulates chemotactic migration of human osteoblasts, human marrow osteoblasts, and U2-OS cells. Bone 18: 53-57.

Liu Y, Lu Y, Tian X, Cui G, Zhao Y, Yang Q, Yu S, Xing G, Zhang B (2009) Segmental bone regeneration using 
an rhBMP-2-loaded gelatin/nanohydroxyapatite/fibrin scaffold in a rabbit model. Biomaterials 30: 6276-6285.

Nazarov R, Jin HJ, Kaplan DL (2004) Porous 3-D scaffolds from regenerated silk fibroin. Biomacromolecules 5: 718-726.

Oktay EO, Demiralp B, Senel S, Cevdet Akman A, Eratalay K, Akincibay H (2010) Effects of platelet-rich plasma and chitosan combination on bone regeneration in experimental rabbit cranial defects. J Oral Implantol 36: 175-184.

Omenetto FG, Kaplan DL (2010) New opportunities for an ancient material. Science 329: 528-531.

Peng H, Usas A, Olshanski A, Ho AM, Gearhart B, Cooper GM, Huard J (2005) VEGF improves, whereas sFlt1 inhibits, BMP2-induced bone formation and bone healing through modulation of angiogenesis. J Bone Miner Res 20: 2017-2027.

Raida M, Heymann A, Günther C, Niederwieser D (2006) Role of bone morphogenetic protein 2 in the crosstalk between endothelial progenitor cells and mesenchymal stem cells. Int J Mol Med 18: 735-739.

Sackstein R, Merzaban JS, Cain DW, Dagia NM, Spencer JA, Lin CP, Wohlgemuth R (2008) Ex vivo glycan engineering of CD44 programs human multipotent mesenchymal stromal cell trafficking to bone. Nat Med 14: 181-187.

Samee M, Kasugai S, Kondo H, Ohya K, Shimokawa H, Kuroda S (2008) Bone morphogenetic protein-2 (BMP-2) and vascular endothelial growth factor (VEGF) transfection to human periosteal cells enhances osteoblast differentiation and bone formation. J Pharmacol Sci 108: 18-31.

Sood S, Gupta S, Mahendra A (2012) Gene therapy with growth factors for periodontal tissue engineering--a review. Med Oral Patol Oral Cir Bucal 17: e301-310.

Thevenot PT, Nair AM, Shen J, Lotfi P, Ko C-Y, Tang L (2010) The effect of incorporation of SDF-1 $\alpha$ into PLGA scaffolds on stem cell recruitment and the inflammatory response. Biomaterials 31: 3997-4008.

Tsioris K, Tao H, Liu M, Hopwood JA, Kaplan DL, Averitt RD, Omenetto FG (2011) Rapid transfer-based micropatterning and dry etching of silk microstructures. Adv Mater 23: 2015-2019.

Vogel G (2011) Mending the youngest hearts. Science 333: 1088-1089.

Wang S, Zhang Z, Zhao J, Zhang X, Sun X, Xia L, Chang Q, Ye D, Jiang X (2009) Vertical alveolar ridge augmentation with beta-tricalcium phosphate and autologous osteoblasts in canine mandible. Biomaterials 30: 2489-2498.

Young S, Patel ZS, Kretlow JD, Murphy MB, Mountziaris PM, Baggett LS, Ueda H, Tabata Y, Jansen JA, Wong M, Mikos AG (2009) Dose effect of dual delivery of vascular endothelial growth factor and bone morphogenetic protein-2 on bone regeneration in a rat critical-size defect model. Tissue Eng Part A 15: 2347-2362.

Zhang W, Wang X, Wang S, Zhao J, Xu L, Zhu C, Zeng D, Chen J, Zhang Z, Kaplan DL, Jiang X (2011) The use of injectable sonication-induced silk hydrogel for VEGF165 and BMP-2 delivery for elevation of the maxillary sinus floor. Biomaterials 32: 9415-9424.
Zhu C, Chang Q, Zou D, Zhang W, Wang S, Zhao J, Yu W, Zhang X, Zhang Z, Jiang X (2011) LvBMP-2 gene-modified BMSCs combined with calcium phosphate cement scaffolds for the repair of calvarial defects in rats. J Mater Sci Mater Med 22: 1965-1973.

Zou D, Zhang Z, Ye D, Tang A, Deng L, Han W, Zhao J, Wang S, Zhang W, Zhu C, Zhou J, He J, Wang Y, Xu F, Huang Y, Jiang X (2011) Repair of critical-sized rat calvarial defects using genetically engineered bone marrow-derived mesenchymal stem cells overexpressing hypoxia-inducible factor-1alpha. Stem Cells 29: 13801390.

Zou D, Zhang Z, He J, Zhang K, Ye D, Han W, Zhou J, Wang Y, Li Q, Liu X, Zhang X, Wang S, Hu J, Zhu C, Zhang W, zhou Y, Fu H, Huang Y, Jiang X (2012) Blood vessel formation in the tissue-engineered bone with the constitutively active form of HIF- $1 \alpha$ mediated BMSCs. Biomaterials 33: 2097-2108.

\section{Discussion with Reviewers}

Reviewer I: The doses added to the silk scaffolds are relatively high for the recruitment in vivo study. Due to the BMPs well known pro-osteoblastic and proosteoclastic effects, higher doses of the BMP can result in a pro-osteoclastic response that could hinder regenerative potential in the model. While this study predominantly looked at early-stage response, the in vivo critical size defect model's bone formation may be affected negatively by pro-osteoclastic triggers. Could the authors comment on any dose response work conducted to determine the dosages used? Was it a volume based ratio between the in vitro chemotaxis model compared to the implanted scaffold volume?

Authors: Firstly, we are sorry for the misdirection and inconvenience caused by omitting the details about the procedures of growth factor loading in the manuscript. Actually, after $20 \mu \mathrm{L}$ of growth factor solution were added in each scaffold, the samples were kept at $4{ }^{\circ} \mathrm{C}$ overnight, and then the redundant solutions were removed using absorbent paper. Consequently, about $20 \%$ of the added growth factors were still left in the scaffolds when implanted in vivo. In addition, in the present study, we initially launched the rabbit skull bone regeneration experiment to evaluate the effects of porous silk scaffolds carrying VEGF and BMP-2. Interestingly, the whole defect region was replaced by mature bone tissue in the $\mathrm{V}+\mathrm{B}$ group, and the structure of the newly formed bone is similar to native bone. Given such a good result, we continued to use the dose for the recruitment in vivo study. So we did not perform any dose response work before, and there is not a volume based ratio. However, further efforts will be taken to study the dose response relationship for stem cells recruitment in vivo. It is indeed important to determine the optimal dosage for enhancing bone regeneration and avoiding the adverse reaction that you mentioned.

Reviewer I: Have the authors looked at or optimised the release rate of the both factors from the scaffolds? Is 
there an inherent temporospatial release profile or are both presented simultaneously to the cells by the scaffolds?

Authors: In this study, VEGF and BMP-2 are mixed together before adding to the scaffolds, so the two factors will be released simultaneously but not in a temporospatial model. In addition, the release profile of growth factor from the porous silk scaffolds has been well documented in our previous study (Karageorgiou, et al., 2006). About $25 \%$ of the initial BMP-2 was retained adsorbed to the scaffold after 1 week under dynamic culture conditions in vitro and the release process can continue for 4 weeks. Thus, silk fibroin is a favourable matrix for the incorporation and delivery of therapeutic agents (Wenk, et al., 2011).

\section{Additional Reference}

Wenk E, Merkle HP, Meinel L (2011) Silk fibroin as a vehicle for drug delivery applications. J Control Release 150:128-141. 